Research, Society and Development, v. 9, n. 8, e899986373, 2020

(CC BY 4.0) | ISSN 2525-3409 | DOI: http://dx.doi.org/10.33448/rsd-v9i8.6373

\title{
Música e concepções de estudantes sobre o papel social atribuído à mulher
}

Music and students' conceptions of the social role attributed to women

La música y las concepciones de los estudiantes sobre el papel social atribuido a la mujer

Recebido: 08/07/2020 | Revisado: 15/07/2020 | Aceito: 19/07/2020 | Publicado: 01/08/2020

Anaquel Gonçalves Albuquerque

ORCID: https://orcid.org/0000-0001-6811-5291

Consórcio CEDERJ/CECIERJ, Brasil

E-mail: anaquelalbuquerque@gmail.com

\section{Resumo}

Compreendendo a importância da música como forma de expressão presente na sociedade desde as civilizações mais antigas, o presente artigo tem por objetivo refletir sobre as relações de poder presentes na sociedade, que geralmente colocam a mulher em posição hierarquicamente inferior ao homem, caracterizando-se pela submissão. Para tanto, trata-se de uma pesquisa de natureza qualitativa, tendo como instrumento de coleta de dados a técnica interativa de observação participante, bem como fazendo uso de recursos de imagem e som para seu respectivo registro. A abordagem se faz também por meio de pesquisa bibliográfica, tomando por base o conceito de gênero para fins de compreensão do papel social atribuído à mulher ao longo da história da humanidade. Para isto nos utilizaremos de relato de experiência realizada em uma escola da Baixada Fluminense, cuja análise de músicas tem contribuído para despertar a criticidade dos estudantes. Através dos estudos realizados e da experiência vivenciada é possível compreender que mesmo diante das várias conquistas obtidas pelas mulheres ao longo dos anos, o papel destinado a elas na contemporaneidade ainda é associado por muitos indivíduos ao casamento e à maternidade. Sendo assim, torna-se de extrema importância o debate destas questões no espaço escolar, a fim de que possamos contribuir para a desconstrução de conceitos associados à gênero, os quais vêm ocasionando o aumento da violência destinada àqueles que não obedecem aos padrões determinados pela sociedade.

Palavras-chave: Música; Reflexão; Mulher. 


\section{Abstract}

Understanding the importance of music as a form of expression present in society since the oldest civilizations, this article aims to reflect on the power relations present in society, which generally place women in a hierarchical position inferior to men, characterized by submission. For this purpose, it is a qualitative research, using the interactive technique of participant observation as a data collection instrument, as well as making use of image and sound resources for its respective registration. The approach is also done through bibliographic research, based on the concept of gender for the purpose of understanding the social role attributed to women throughout human history. For this, we will use an experience report held at a school in the Baixada Fluminense, whose music analysis has contributed to awakening the students' criticality. Through the studies carried out and the lived experience it is possible to understand that even in view of the various achievements obtained by women over the years, the role assigned to them in contemporary times is still associated by many individuals with marriage and motherhood. Thus, it is extremely important to debate these issues in the school space, so that we can contribute to the deconstruction of concepts associated with gender, which have been causing an increase in violence aimed at those who do not obey the standards determined by society.

Keywords: Music; Reflection; Woman.

\section{Resumen}

Entendiendo la importancia de la música como una forma de expresión presente en la sociedad desde las civilizaciones más antiguas, este artículo tiene como objetivo reflexionar sobre las relaciones de poder presentes en la sociedad, que generalmente colocan a las mujeres en una posición jerárquica inferior a los hombres, caracterizada por sumisión. Para ello, se trata de una investigación cualitativa, que utiliza la técnica interactiva de observación participante como instrumento de recopilación de datos, además de utilizar recursos de imagen y sonido para su respectivo registro. El enfoque también se realiza a través de la investigación bibliográfica, basada en el concepto de género con el fin de comprender el papel social atribuido a las mujeres a lo largo de la historia humana. Para esto, utilizaremos un informe de experiencia realizado en una escuela en la Baixada Fluminense, cuyo análisis musical ha contribuido a despertar la criticidad de los estudiantes. Mediante los estudios realizados y la experiencia vivida, es posible comprender que, incluso en vista de los diversos logros obtenidos por las mujeres a lo largo de los años, muchas personas aún asocian el papel que se les ha asignado en los tiempos contemporáneos con el matrimonio y la maternidad. 
Siendo así, es extremadamente importante debatir estos temas en el espacio escolar, para que podamos contribuir a la deconstrucción de conceptos asociados con el género, que han estado causando un aumento de la violencia dirigida a aquellos que no obedecen los estándares determinados por la sociedad.

Palabras clave: Música; Reflexión; Mujer.

\section{Introdução}

De acordo com a Lei de Diretrizes e Bases da Educação Nacional (LDB nº 9.394), aprovada em 20 de dezembro de 1996, em seu artigo 26, parágrafo $2^{\circ}$ : "O ensino da arte constituirá componente curricular obrigatório, nos diversos níveis da educação básica, de forma a promover o desenvolvimento cultural dos alunos." Porém, embora geralmente não vivenciemos esta realidade no contexto escolar, não basta apenas que a Arte faça parte do currículo das escolas. É preciso vivenciar a Arte. É preciso gerar perguntas. E a primeira pergunta a ser feita é: De que maneira nossas escolas têm contribuído para despertar estes questionamentos?

Certamente uma das formas possíveis para despertar a criticidade nos alunos consiste no desenvolvimento de ações que favoreçam o desenvolvimento social, cultural e intelectual, assim como despertando o interesse pelo conhecimento, por meio das várias formas de linguagem e expressão existentes em nosso meio e, por fim, apropriando-se delas.

Entre as várias expressões de Arte encontradas em nossa sociedade, a música se destaca como parte integrante da formação humana, caracterizando uma forma de linguagem que faz parte da cultura humana desde tempos remotos (Brito, 2003). Castro e Teixeira (2020) inclusive ressaltam a relação existente entre a inserção da música no cotidiano quanto ao favorecimento da otimização de sentidos, impressões e concordância no que tange à existência humana.

Sendo assim, o presente trabalho tem por objetivo refletir sobre as relações de poder presentes na sociedade, utilizando-se para isto de relato de experiência realizada em um Centro Integrado de Educação Pública (CIEP) localizado no Rio de Janeiro, mais especificamente na Baixada Fluminense, que tem realizado aulas motivadoras por meio da utilização da música, enquanto instrumento lúdico de reflexão. Cumpre-nos ressaltar que a música em si não faz parte do currículo da instituição, sendo utilizada apenas como recurso didático e metodológico, em virtude das inúmeras possibilidades de aprendizagem que se dão por meio do seu respectivo uso na prática docente. 
No contexto apresentado, a música "Desconstruindo Amélia", de autoria de Pitty, é utilizada para refletir sobre as relações de poder existentes, nos remetendo a Góes (2009), que enfatiza a importância da música como recurso a ser utilizado no processo pedagógico visando o desenvolvimento integral do estudante enquanto ser social. Desta forma, esperamos contribuir para suscitar um olhar crítico sobre o papel social que é atribuído à mulher, no qual geralmente é destinada à esfera doméstica, de modo que o afastamento deste espaço é marcado por um viés preconceituoso e associado a uma degradação moral, apesar das conquistas obtidas ao longo dos anos, como ressaltam Beauvoir (2019) e Louro (1995).

\section{Gênero e as Relações de Poder}

De acordo com estudos realizados, vivenciamos uma trajetória histórica na qual o papel social atribuído à mulher se caracteriza por cuidar da casa e se responsabilizar pela educação dos filhos, estando sempre em posição subalterna ao homem, que deve atuar como provedor do lar.

Neste contexto, Beauvoir (2019) nos traz a reflexão sobre o espaço da mulher na sociedade, que é representado pelo casamento e maternidade, evidenciando um contexto de opressão, em que embora as mulheres tenham conquistado alguns direitos, ainda na modernidade estão presentes os reflexos desta luta por reconhecimento e busca por igualdade, destacando-se as importantes contribuições do movimento feminista para a obtenção destas conquistas.

Santana e Benevento (2013) ressaltam a percepção de diferenças entre os sexos desde a infância em si, ocorrendo por meio das próprias brincadeiras infantis, onde a panelinha, as bonecas e a vassoura são sutilmente destinadas às meninas, como uma orientação prévia do papel que deverá ser desenvolvido por elas, no que tange à maternidade e cuidados com a casa, enquanto ao menino são dados carrinhos, bicicleta, caminhão, carrinho, estando relacionados a instrumentos de força e poder e reafirmando o papel de provedor do lar. Sobre isto, Strey (2017) destaca o reforço dado à preservação da virilidade masculina, citando que ao longo da história os homens são educados, socializados e treinados para resolverem problemas independente das formas que se utilizem para esta prática. Ou, seja, mesmo que necessitem utilizar a força para o alcance deste objetivo.

Ao chegar na escola, estas hierarquizações de gênero continuam prevalecendo por meio da ênfase dada às atividades realizadas, na forma de se portar neste espaço e até mesmo no estímulo em disciplinas específicas, como é o caso das ciências exatas, que geralmente 
associam a figura masculina àquele que obtém melhor compreensão de conteúdos específicos, sendo esta uma situação que nos reporta ao questionamento trazido por Garbi (2006, p.308), de que "seria possível tirar disso alguma conclusão, além da que as mulheres apenas tiveram historicamente muito menos oportunidades e estímulos que nós homens?"

Configurando um conceito de alta complexidade, por regular as relações entre homemmulher, homem-homem e mulher-mulher, gênero representa uma construção sociocultural, conforme cita Priori (2007). Scott (1995) também nos auxilia na compreensão do conceito de gênero, associando-o a uma percepção sobre as diferenças sociais, que tanto vem contribuindo para hierarquizar homens e mulheres perante um ponto de vista que se apresenta de forma "engessada", mesmo diante das contínuas mudanças da sociedade. Tal cenário nos remete à importância da escola desenvolver espaços de reflexão e discussão sobre os papeis sociais que nos são transmitidos, na busca pela desnaturalização deste processo, como destacam Louro (1995) e Priori (2007).

Assim, romper com padrões que determinam como deve ser o comportamento de homens e mulheres não é algo fácil, até mesmo porque a escola sempre esteve associada a um espaço responsável por instituir o lugar de cada um na sociedade, determinando o que compete a cada indivíduo fazer (Louro, 1995). Surge, portanto, a necessidade da escola contribuir para a desconstrução destes papeis, no sentido de estimular o respeito ao próximo e às escolhas feitas por cada indivíduo, atuando ainda como espaço de ensino-aprendizagem proporcionado por meio de debates, reflexões e busca por soluções, além de servir como estímulo para questionamentos, assim como é proposto na experiência relatada ao longo deste trabalho, que se utiliza da música como base para a promoção de mudanças.

A partir de então, tomando a música como eixo norteador do projeto desenvolvido, apresentamos a seguir importantes aspectos de sua utilização para suscitar questionamentos sobre o papel social atribuído à mulher ao longo do tempo. Destacamos, ainda, características da escola na qual realizou-se o projeto que deu origem a este artigo e dos sujeitos envolvidos, assim como a metodologia empregada e a descrição das etapas que formam o projeto em si.

\section{A Música e suas Contribuições para a Compreensão do Papel Social Atribuído à}

\section{Mulher}

Stefani (1987, p.13) afirma que a música está presente na vida das pessoas nos mais diferentes tempos e espaços, de forma que "vivemos mergulhados em sons. E em música. Em todo lugar, a qualquer hora. Respiramos música sem nos darmos conta disso.” Bréscia (2003) 
também corrobora para este contexto, destacando que a música está presente em quase todas as manifestações sociais e pessoais do indivíduo desde os tempos mais longínquos. Assim, ao inserir a música no contexto educacional, esta pode contribuir como instrumento facilitador no processo de aprendizagem, favorecendo também quanto ao despertar da atenção dos estudantes, por motivar até mesmo aqueles que se dispersam com facilidade, assim como estimular que sejam expressos sentimentos.

De acordo com a lei nacional $\mathrm{n}^{\mathrm{o}}$ 11.769/2008, que torna obrigatório o ensino de música nas escolas de educação básica, esta passa a ser compreendida como uma área do conhecimento caracterizada por estudo, reflexo e prática. Bastian (2009) também destaca a importância de sua respectiva utilização no cotidiano escolar, por favorecer que os estudantes se tornem menos agressivos e mais integrados ao espaço escolar. Desta forma torna-se explícita a necessidade de contemplar no projeto político pedagógico das escolas a utilização da música como instrumento facilitador de aprendizagem, dadas as contribuições que esta prática pode proporcionar para o desenvolvimento sociocognitivo dos estudantes.

\section{O Local da Pesquisa}

A pesquisa foi desenvolvida em um CIEP localizado em Nova Iguaçu, na Baixada Fluminense, no estado do Rio de Janeiro. A instituição possui 325 alunos matriculados no ensino médio, que é ofertado na modalidade regular, bem como em horário integral, com foco no Empreendedorismo.

A proposta de horário integral implementada na instituição traz consigo um modelo pedagógico no qual os componentes curriculares são organizados em áreas do conhecimento (Linguagens, Matemática, Ciências Humanas e Ciências da Natureza) e núcleo articulador (formado pelas disciplinas Projeto de Vida, Empreendedorismo e Projeto de intervenção e pesquisa), de forma a contemplar o desenvolvimento de projetos pelos alunos, por meio da orientação docente.

No entanto, destaca-se que a instituição escolar não dispõe de componente curricular direcionado à música e no que tange ao ensino das Artes, esta disciplina é ofertada apenas ao longo do primeiro ano do ensino médio. Entretanto, sendo a música uma das formas de expressão das Artes e dadas as suas contribuições para o desenvolvimento do indivíduo, a instituição preza por sua utilização nos anos seguintes de escolaridade, fazendo uso deste recurso pedagógico ao longo dos 3 anos de duração desta etapa de ensino. 


\section{Metodologia}

A pesquisa realizada desenvolveu-se por meio da utilização de métodos qualitativos, sendo caracterizados pela busca, enquanto princípio do conhecimento, a partir da compreensão das complexas relações que fazem parte da realidade social (Araújo, Oliveira \& Rossato, 2017).

Trata-se, ainda, de uma pesquisa exploratória, por possibilitar que sejam desenvolvidos, esclarecidos e modificados conceitos e ideias, com vistas a hipóteses pesquisáveis para estudos posteriores (Gil, 2008).

Os recursos metodológicos utilizados para proporcionar a reflexão sobre o papel atribuído à mulher ao longo dos anos foram celular (possibilitando que os alunos ouvissem a letra da música escolhida para análise, bem como para registro de toda a aula), debates, confecção de cartazes, computadores (utilizados para pesquisa de letras de música sobre o tema, com a finalidade de enriquecer a aprendizagem) e exposição de trabalhos.

\section{Os Sujeitos da Pesquisa}

Como sujeitos da pesquisa tivemos 35 alunos do terceiro ano do ensino médio com foco em Empreendedorismo, matriculados em regime de horário integral. O critério utilizado para selecionar esta turma se deu por conta da disponibilidade de tempo para realização de projetos variados, visto que por se tratar de horário integral, há tempos vagos que geralmente são aproveitados para oportunizar novas aprendizagens. Corrobora para esta escolha o perfil de liderança verificado na maior parte dos alunos, que favorece quanto à multiplicação dos conhecimentos obtidos ao longo do projeto.

As atividades desenvolvidas fizeram parte de um projeto realizado pela disciplina Projeto de vida, que tem por objetivo principal preparar o aluno para o mercado de trabalho, por meio da realização de projetos que despertem a criticidade e o respeito nas relações interpessoais, como um dos critérios para a convivência harmoniosa em qualquer espaço social. Castro e Teixeira (2020) inclusive citam a importância da música enquanto ferramenta didática que pode ser mais explorada no percurso pedagógico e neste contexto a música se tornou o eixo central das aulas desenvolvidas ao longo do projeto, proporcionando reflexões e debates, embora não configure como elemento central da disciplina em si. 


\section{Sensibilizando e Possibilitando Reflexões}

A disciplina Projeto de vida configura como parte diversificada do currículo das escolas estaduais de horário integral do Rio de Janeiro, com foco em Empreendedorismo. Um de seus principais objetivos enquanto parte integrante do currículo escolar consiste na prática de despertar nos estudantes a reflexão sobre seus anseios e objetivos, fazendo com que estes estabeleçam metas e se organizem em prol deste alcance, aprendendo a planejar e desenvolver características como determinação, autoconfiança e persistência durante todas as suas ações. Acredita-se que por meio das aulas desta disciplina torna-se possível contribuir para a compreensão dos critérios necessários para a inserção dos indivíduos no mercado de trabalho, considerando os impactos desta escolha na sociedade, assim como o surgimento das novas tendências e profissões, as quais podem vir a influenciar em nossas escolhas.

Castro e Teixeira (2020, p.16) afirmam que "a música pode ser utilizada tanto quanto ferramenta para o desenvolvimento de conhecimentos pertinentes a todas as áreas do conhecimento, quanto como fonte de ampliação cultural e epistemológica.” Neste intuito, a professora da disciplina Projeto de vida trouxe para a sala de aula a letra da música "Desconstruindo Amélia", convidando os alunos para ouvir e refletir sobre a mensagem transmitida. Por meio da letra desta música, da autoria de Pitty, tornou-se possível verificar que a prática reflexiva pode ser trabalhada em todo o tempo, levando ao estímulo da criticidade de forma prazerosa e instigante.

De acordo com a letra da música apresentada, proporcionou-se a reflexão sobre o processo de construção social pautado na dominação patriarcal, que por sua vez cria e instaura o 'ser mulher' como uma condição 'natural', marcada pela inferioridade aos homens e fragilidade, expondo-a à inúmeras formas de dominação e controle, no qual ser feminina na perspectiva patriarcal é sinônimo de submissão, doçura, fragilidade e sujeição às normas e expectativas sociais.

Nos primeiros versos da música temos o cumprimento de etapas destinadas à mulher, expressas por práticas como cuidar das tarefas de casa e dos filhos, reforçando os significados culturais que são dados aos sexos e a concepção de que cabe à mulher "participar dessa realidade misteriosa e ameaçada que é a feminilidade.” (Beauvoir, 2019, p.13)

Importante destacar que já no início da música foram perceptíveis as inúmeras contribuições dadas pelos estudantes, que descreveram suas rotinas e debateram sobre as diferenças existentes entre as tarefas diárias destinadas a cada um deles, de forma que até mesmo irmãos que estudavam na mesma turma questionaram as próprias práticas exercidas 
por eles, de maneira que a um (à menina) era dada pela mãe, que trabalhava todos os dias, a tarefa de esquentar a comida e arrumar a casa ao retornar da escola e, à seu irmão, "tomar conta" das irmãs, para que não fossem para a rua. Compreende-se a preocupação desta mãe, ao ter que trabalhar e deixar seus filhos tão novos em casa sozinhos (a menina tinha 16 e o irmão 17 anos respectivamente). O que serve como alvo de crítica e reflexão é a reprodução dos papeis sociais expressos na fala desta mãe, visto que nada impede que o filho, do sexo masculino, contribua com as tarefas de manutenção da casa. Assim, a discussão seguiu entre os alunos, evidenciando que a desigualdade imposta aos gêneros ainda se faz presente na família contemporânea, por meio da imposição de expectativas de papéis de gênero, enquanto cenas comuns do cotidiano (Praun, 2011).

Outras alunas também fizeram questão de citar falas comumente vindas das mães, do tipo: "Homem não gosta de mulher relaxada!”, “Vê se cozinha direito, senão seu marido vai te largar", "Quero ver quando você tiver filhos...” ou até mesmo “ Tomara que case logo! Assim você vai aprender o que uma mulher tem que fazer!”. Estas falas, vindas de diferentes alunas, retratam a diferenciação dos papeis sociais impostos aos gêneros e também despertam inquietações nas alunas, que enfatizam fazer parte de uma outra geração e que o casamento não é a única opção de vida, sendo inaceitável que as mulheres sejam “manipuladas" para agir sempre em função do que se espera delas. Carolina (nome fictício para a aluna C., como finalidade de preservação da imagem da estudante) cita inclusive que casamento não faz parte de seu projeto de vida atual, pois primeiro pretende formar-se na faculdade, ingressar no mercado de trabalho, para somente após estas etapas constituir família. Outras alunas da turma, em sua maioria, também concordam entre si com o posicionamento da colega, relatando que pretendem fazer o mesmo, pois após o casamento e filhos, dificilmente há tempo de cuidar das aspirações pessoais e o próprio ingresso no mercado de trabalho se torna mais difícil, já que é preciso dividir o tempo entre trabalho e família.

Estas concepções denotam o reconhecimento da superioridade masculina e reafirmam uma cultura patriarcal, na qual desde a mais tenra infância o sexo biológico serve como base para a determinação de atividades e comportamentos a serem realizados (Lima et al, 2017). Constata-se, ainda, que as próprias mães são vítimas da cultura patriarcal que tem sido reproduzida ao longo dos anos, mas que pelas concepções apresentadas durante a realização deste projeto começam a ser questionadas e quem sabe sirvam de parâmetros para novas posturas.

Um aspecto que nos chama atenção na música escolhida pela professora para trabalhar o papel social atribuído à mulher ao longo dos anos é que a referida canção possibilita pensar 
na mulher enquanto mãe e dona de casa, expresso nos versos " $O$ ensejo a fez tão prendada/ Ela foi educada pra cuidar e servir". Lerner (2019, p.43) inclusive destaca que "a tradição tradicionalista (...) vê a maternidade como a maior meta das mulheres, definindo, assim, como desviantes mulheres que não se tornam mães." Ou seja, não basta ser mulher. É preciso cumprir os papeis determinados para esta, visando ser aceita na sociedade.

Outros versos da música também nos permitem refletir sobre um processo de mudança comportamental, caracterizado por "Vira a mesa, assume o jogo/ Faz questão de se cuidar/ Nem serva, nem objeto/ Já não quer ser o outro/ Hoje ela é um também." Através destas expressões, nos é possibilitado pensar que esta mesma mulher submissa, que serviu como inspiração para a letra da música, resolve mudar e cuidar também um pouco mais de si mesma. Sobre isto, Saffioti (1987, p.8) destaca que "a sociedade delimita com bastante precisão, os campos em que pode operar a mulher, da mesma forma em que escolhe os terrenos em que pode atuar o homem", e nestas delimitações o papel de dona de casa geralmente é tão interiorizado pela mulher em si que qualquer pretensão de mudança comportamental vira alvo de muita análise até que se dê de fato sua efetivação.

Os versos "Já não quer ser o outro/ Hoje ela é um também" chamaram a atenção dos alunos sobre as várias formas da mulher se portar para agradar desde o namorado até o futuro marido. As estudantes relataram que muitas vezes ocorre a renúncia aos sonhos e objetivos para dar conta de um casamento perfeito, a começar pela rotina de cuidados com a casa, como se esta responsabilidade fosse apenas da mulher, sendo necessário romper com estes paradigmas. Alguns estudantes do sexo masculino citaram que os conflitos geralmente ocorrem em virtude da mulher não conseguir "dar conta" de duas coisas ao mesmo tempo (casa e trabalho), ficando até mesmo com uma aparência desleixada. Neste momento, as meninas que compõem a turma destacaram a importância do homem contribuir com as tarefas de casa, pois se a mulher muitas vezes se vê nesta situação de desleixo, isto pode ter sido ocasionado pelo excesso de tarefas a ela destinada. Contexto este que nos leva à definição dos papeis e comportamentos destinados aos sexos, que são expressos em valores, costumes e leis que se tornaram parte da construção social e do sistema explicativo (Lerner, 2019). Neste aspecto, Saffioti (1987) também nos serve de base para refletir sobre as falas apresentadas, pois a autora destaca que mesmo no exercício de função remunerada fora do lar, a mulher continua sendo responsabilizada pela educação dos filhos e demais tarefas de casa, retratando a naturalização de um processo social, que investe na 'identidade básica' entre todas as mulheres, como também destaca a autora.

A discussão apresentada se deu de forma muito participativa, com argumentos em 
defesa da mulher e por meio do debate em torno de questões como cuidados excessivos com a aparência enquanto atributo exclusivamente feminino, participação masculina nas tarefas da casa e relacionamento saudável, proporcionado pelo respeito e valorização mútua, buscando desconstruir o discurso de que a mulher deveria estar sempre bela para os homens e de que estes seriam os encarregados dos serviços mais pesados relacionados à infraestrutura da casa, enquanto as mulheres seriam responsáveis por cozinhar, limpar, entre outras tarefas domésticas, como destaca Cursino (2010).

Os versos "A despeito de tanto mestrado/ Ganha menos que o namorado/ E não entende porque" também levantaram várias discussões a respeito das diferenças e desigualdades de gênero no que tange à esfera profissional, revelando a pressão exercida pelo patriarcado, que continua ofertando às mulheres empregos geralmente mal remunerados e não raras vezes sendo análogos ao trabalho doméstico. (Saffioti,1987; Folbre,1994). Cumpre ressaltar que esta discriminação salarial corrobora para o aumento da desigualdade social, justiça social e pobreza quanto a atividade econômica de um país ou região, como destacam Barros, Ramos e Santos, (1995), apud Baptista (2000). Acrescenta-se que embora a mulher tenha conseguido ao longo dos anos se inserir no mercado de trabalho, esta ainda continua em desvantagem em relação ao gênero masculino, ainda que com escolaridade relativamente superior (Pinheiro et al., 2008), expressando o alto nível de discriminação a que a mulher se submete cotidianamente. Discriminação esta reforçada por meio de "preconceitos milenares, transmitidos através da educação, formal e informal, às gerações mais jovens." (Saffioti, 1987, p. 28)

Compreendendo que a escola representa um espaço rico em experiência, a temática abordada por meio da música "Desconstruindo Amélia", proporcionou que os alunos participassem de forma mais ativa da aula, bem como estimulou a aprendizagem de forma prazerosa, visto que além do debate, os alunos também foram convidados a pesquisar no laboratório de Informática da instituição outras letras de música que levassem a refletir sobre as relações de poder existentes entre os gêneros. Cabe destaque ao papel representado pela utilização da música na prática docente, o qual certamente exerce influência no desenvolvimento de qualquer indivíduo, "seja no aspecto religioso, moral e social, o que contribuiu para a aquisição de hábitos e valores indispensáveis ao uso da cidadania." (Loureiro, 2011, p.5)

Acrescenta-se que a partir da letra da música apresentada, seguida de ato reflexivo e debate, novas letras de música surgiram por meio da pesquisa e alguns alunos inclusive escreveram poemas retratando esta realidade, sendo realizados os devidos registros em 
cartolina, por meio da confecção de cartazes que foram colocados nos corredores da escola, formando uma grande exposição e evidenciando a apropriação de conceitos que certamente contribuirão para mudanças quanto à forma de pensar e agir dos estudantes envolvidos neste projeto.

Tornou-se possível, ainda, perceber que o projeto realizado pela disciplina Projeto de vida logrou resultados altamente positivos, pois os participantes das atividades propostas realizaram posteriormente apresentação de filmes e encontros com outros alunos da instituição escolar para abordagem do papel social atribuído à mulher ao longo da história, disseminando os conhecimentos obtidos e propiciando que outros alunos, de diferentes etapas do ensino médio, refletissem sobre as desigualdades existentes na sociedade a partir do conceito de gênero. Para o cumprimento deste objetivo, a música se apresentou como um diferencial, ao promover uma sensação de bem-estar nos alunos e tornar o ambiente mais agradável e favorável à obtenção de novos aprendizados, conforme afirmam os próprios estudantes.

As reflexões que iniciaram com o desenvolvimento do projeto se estenderam no decorrer dos meses seguintes à realização deste, estimulando novos debates e questionamentos. Além disto, evidenciou-se que a abordagem de gênero e dos papeis sociais atribuídos à mulher continua sendo uma temática extremamente necessária nos dias atuais, pois em uma sociedade na qual ainda é possível encontrar pessoas que negam a existência de preconceitos contra a mulher, a busca por problematização e desnaturalização deste processo se apresenta como uma das principais funções da escola.

\section{Considerações Finais}

Tendo por objetivo refletir sobre as relações de poder presentes na sociedade, o relato de experiência descrito no presente artigo expõe que é possível elaborar e desenvolver projetos voltados para a superação de toda e qualquer forma de preconceito ou discriminação contra a mulher, a fim de que caminhemos em busca de uma sociedade mais justa e igualitária. Neste sentido, a discussão e abordagem desta temática pode contribuir para a promoção da dignidade humana e valorização da mulher, rompendo com o estereótipo de que seu papel social seria tão somente destinado às tarefas de casa e educação dos filhos.

Embora a abordagem de temas como este não seja de fácil aceitação social, por se tratar de conceitos arraigados pela sociedade e de difícil desconstrução, a escola caracteriza um espaço privilegiado para a promoção de debates e reflexão, podendo contribuir para o 
combate às desigualdade existentes entre os gêneros, a partir da compreensão de que não se trata de negar as diferenças biológicas existentes entre os sexos, mas de reconhecer que estas diferenças não justificam a hierarquização imposta a homens e mulheres ao longo do tempo por meio dos papeis que estes devem assumir na sociedade.

Assim, a partir das concepções dos estudantes e dos estudos realizados pelos importantes teóricos que serviram de base para fundamentar as discussões sobre gênero, verifica-se que este assunto precisa ser mais trabalhado no espaço escolar, principalmente diante da transmissão de valores patriarcais geralmente transmitidos pela sociedade, pois apesar das recentes conquistas obtidas pelas mulheres ao longo dos últimos anos, ainda assim torna-se visível um cenário de desigualdade e hierarquização. Cenário este reproduzido nos discursos e motivado principalmente pela discriminação presente nas mais diversas esferas sociais, expressando a necessidade de políticas que assegurem a igualdade de direitos sociais e o combate a qualquer forma de preconceito.

Neste sentido, a escola pode contribuir para a prática reflexiva e desconstrução dos papeis sociais atribuídos a homens e mulheres, favorecendo a expressão de emoções, bem como contribuindo para a formação integral do indivíduo. Para isto, a utilização da música no cotidiano escolar se apresenta como uma possibilidade de mudança, ampliando a capacidade expressiva, perceptiva e reflexiva de estudantes e professores e propiciando a apreensão e construção de conhecimentos, ao invés de mera reprodução destes.

Assim, por meio da pesquisa realizada e tendo por base a discussão promovida pelos debates e demais atividades realizadas com a turma, juntamente às vivências sociais apresentadas pelos participantes do projeto, tornou-se explícita que a imposição de papéis de gênero no contexto familiar por meio da prática de socialização e orientação quanto à educação doméstica permanecem até os dias atuais, representando que este não é um processo de rápida desconstrução.

Enfatiza-se que o presente estudo não esgota as possibilidades de discussão acerca das relações de poder presentes na sociedade, mas pretende contribuir para suscitar a continuidade do debate sobre esta questão, ressaltando a importância da descoberta e efetivação de novas práticas que fomentem a sensibilização de crianças e jovens, das mais distintas realidades, para a desconstrução dos papeis sociais atribuídos à mulher. Desta forma, a música como recurso pedagógico utilizado para o despertamento da criticidade e ampliação da visão de mundo dos estudantes, pode de fato contribuir para a formação da identidade e autonomia, baseada na reflexão sobre conceitos arraigados pela sociedade. 


\section{Referências}

Araújo, C. M., Oliveira, M.C.S. L., \& Rossato, M. (2017). O Sujeito na Pesquisa Qualitativa: Desafios da Investigação dos Processos de Desenvolvimento. Psicologia: Teoria e Pesquisa, 33.

Barbosa, A. M.(1996). A imagem no ensino de arte. Perspectiva, S.P.

Bastian, H. (2009). Música na escola: a contribuição do ensino de música no aprendizado e no convívio social da criança. Paulinas, S.P.

Baptista, D. B. D. A. (2000). Diferenciais de rendimentos e discriminação por sexo no mercado de trabalho brasileiro na década de 90. In: Anais eletrônicos do XII Encontro nacional da Associação Brasileira de Estudos Populacionais. Caxambu, MG: ABEP. Recuperado de www.abep.nepo.unicamp.br/docs/anais/pdf/2000/Todos /Diferenciais\%20de\%20Rendimento\%20e\%20Discrimina\%C3\%A7\%C3\%A3o\%20por\%20se xo\%20no\%20Mercad.pdf.

Beauvoir, S. (2019). Segundo Sexo: fatos e mitos. 5.ed. Nova Fronteira, Rio de Janeiro.

Bréscia, V. L. P. (2003). Educação musical: Bases psicológicas e ação preventiva. Átomo, São Paulo.

Brito, T. A. (2003). Música na Educação Infantil: propostas para a formação integral da criança. Editora Fundação Petrópolis, São Paulo.

Brasil. (2008). Lei $\mathrm{n}^{\mathrm{o}} 11.769$, de 18 de agosto de 2008. Brasília/DF. Dispõe sobre a obrigatoriedade do ensino de música na educação básica. Recuperado de http://www.planalto.gov.br/ccivil_03/_ato2007-2010/2008/lei/111769.htm. Acesso em : 05 de Maio de 2020.

Brasil. (1996). Lei n. 9.394/96, de 20 de dezembro de 1996. Institui as diretrizes e bases da educação nacional. Recuperado de http://portal.mec.gov.br/arquivos/pdf/diretrizes.pdf. 
Castro, R. E., \& Teixeira, M. R. F. (2020). Música na Educação: uma possibilidade a ser ampliada no cenário nacional. Research, Society and Development, 9(7): 1-20.

Cursino, R. (2010). Relações de gênero em famílias heterossexuais de classe média da cidade do Recife: sobre discursos e posicionamentos. Dissertação (Mestrado), Programa de Pósgraduação em Psicologia, Universidade Federal de Pernambuco, Recife. Recuperado de https://repositorio.ufpe.br/bitstream/123456789/8644/1/arquivo810_1.pdf .

Folbre, N. (1994). Who pays for the kids? Roudledge, London.

Garbi, G. G. (2006). A Rainha das Ciências: um passeio histórico pelo maravilhoso mundo da Matemática. Editora Livraria da Física, São Paulo.

Gil, A. C. (2008). Como elaborar projetos de pesquisa. 4. ed. Atlas, São Paulo.

Góes, R. S. (2009). A música e suas possibilidades no desenvolvimento da criança e o aprimoramento do código linguístico. Revista do Centro de educação à distânciaCEAD/UDESC. 2 (1), 27-43.

Lerner, G. (2019). A criação do patriarcado: história da opressão das mulheres pelos homens. Cultrix, São Paulo.

Lima, F., Voig, A. E. G., Feijó, M. R., Camargo, M. L., \& Cardoso, H. F. (2017). A influência da construção de papeis sociais de gênero na escolha profissional. Rev. Bras. Psicol. Educ. Araraquara, 19(1), 33-50.

Louro, G. L. (1995). Gênero, história e educação: construção e desconstrução. 20 (2), 101132. Educação e realidade, Porto Alegre.

Pinheiro, L., Fontoura, N. O., Querino, A. C., Bonetti, A., \& Rosa, W.(2008). Retrato das desigualdades de gênero e raça. IPEA, Brasília.

Praun, A. G. (2011). Sexualidade, gênero e suas relações de poder. Revista Húmus, 1(1), 5565. 
Priori, C. (2007). Retratos da violência de gênero: denúncias na Delegacia da Mulher de Maringá. Eduem. Maringá.

Saffioti, H. I. B. (1987). O poder do macho. Moderna, São Paulo.

Santana, V. C., \& Benevento, C. F. (2013). O conceito de gênero e suas representações sociais. Educação Física e esportes. Buenos Aires, 1-1. Recuperado de www.efdeportes.com/efd176/o-conceito-de-genero-e-suas-representacoes-sociais.htm.

Scott, J. (1995). Gênero: uma categoria útil de análise histórica. 20 (2), 1-29. Educação \& Realidade, Porto Alegre.

Stefani, G. (1987). Para entender a música. Rio de Janeiro: Globo.

Strey, M. N. (2017). A violência de gênero é um dos fenômenos mais democráticos que existem. Instituto Humanista UNISINOS. São Leopoldo.

\section{Porcentagem de contribuição de cada autor no manuscrito}

Anaquel Gonçalves Albuquerque - 100\% 